\title{
Why are Extraverts more Popular? : Oral Fluency mediates the Effect of Extraversion on Popularity in Middle Childhood
}

\section{Ilmarinen, Ville}

2015

Ilmarinen , V , Vainikainen , M-P , Verkasalo , M \& Lönnqvist , J-E 2015 , ' Why are

Extraverts more Popular? Oral Fluency mediates the Effect of Extraversion on Popularity in

pÿMiddle Childhood ' , European Journal of Personality , vol. 29 , no. 2 , pp. 138 151 . https://doi.org/10.1002/per.19

http://hdl.handle.net/10138/298940

https://doi.org/10.1002/per.1982

unspecified

acceptedVersion

Downloaded from Helda, University of Helsinki institutional repository.

This is an electronic reprint of the original article.

This reprint may differ from the original in pagination and typographic detail.

Please cite the original version. 
Running Head: Why are Extraverts more Popular?

Why are Extraverts more Popular? Oral fluency mediates the effect of extraversion on popularity in middle childhood

\author{
Ville-Juhani Ilmarinen \\ Institute of Behavioural Science, University of Helsinki, Finland \\ Mari-Pauliina Vainikainen \\ Centre for Educational Assessment, University of Helsinki, Finland
}

Markku Verkasalo

Institute of Behavioural Science, University of Helsinki, Finland

Jan-Erik Lönnqvist

Swedish School of Social Science, University of Helsinki, Finland

Correspondence concerning this paper should be sent to Jan-Erik Lönnqvist, Swedish School of Social Science, University of Helsinki, PO BOX 16, 00014 University of Helsinki, Finland. Phone: +35891911. Email: jan-erik.lonnqvist@ helsinki.fi 


\begin{abstract}
In a sample of 7 - to 8 -year-old children $(N=760)$, we examined the associations between personality traits, oral fluency, and sociometric popularity. Extending upon research conducted with older populations, we found parent ratings of Extraversion at age seven to predict popularity one year later. More importantly, we expected and found teacher rated oral fluency to partially mediate the positive association between Extraversion and popularity. This mediation effect was independent of psychometrically assessed working memory, academic skills and gender. Our results can be interpreted as suggesting that a Matthew Effect, similar to the one proposed for early reading skills and cognitive ability, may be operating in the domain of social competence.
\end{abstract}




\section{Introduction}

Why are some children popular and others unpopular? In recent years, the evidence has accumulated that a certain personality disposition; i.e., Extraversion, is associated with being popular. However, the explanation that certain kids are popular because they are extraverted begs the questions of why those who are extraverted are more popular. The focus of the present research is on the mechanisms through which children's personality may influence their popularity. In adulthood, behavioral manifestations of Extraversion, such as strength of voice, have been associated with positive first impressions (Back, Schmukle, \& Egloff, 2010), which could in part help explain the association between Extraversion and popularity. However, other mechanisms may be at play in childhood, especially in contexts such as in the classroom, in which first impressions are likely to be less important than in many other contexts - whereas first impressions may in some context determine whom people approach, sit next to, or engage in conversation with, thereby determining opportunities to learn to know people, children attending the same class will over time learn to know all of their classmates. We will investigate, in a sample of seven- to eight-year-olds, whether (a) Extraversion, already at the beginning of middle childhood, is associated with popularity; and (b) whether the predicted association between Extraversion and popularity can be explained by the greater oral fluency of extraverts.

\section{Popularity}

In general terms, popularity is characteristic of an individual that reflects whether the individual is generally liked, accepted, and preferred as an interaction partner. It is a form of social status that is unilateral (as opposed to reciprocated social relation between two individuals); it reflects how others perceive the individual and how much they like the individual (Bukowski, Pizzamiglio, Newcomb, \& Hoza, 1996). Although popularity is derived from the group, it is inevitably influenced by the behaviors and characteristics of the individual. 
Popularity as a concept reflective of peer status is commonly studied in one of two somewhat distinct forms. The focus of the present study is on "sociometric popularity" (later also referred to as "popularity"), which is distinguished from "perceived popularity" (Parkhurst \& Hopmeyer, 1998). Sociometric popularity is measured by items such as "this person is likeable" or "I like to play/work with this person" and perceived popularity by items such as "how popular is this person?" (Cillessen \& Mayeux, 2004). Sociometric popularity is weighted towards likeability and preference, whereas perceived popularity is more a reflection of visibility and social centrality (Parkhurst \& Hopmeyer, 1998). Although the different types of popularity are interrelated, they also have distinct predictors, correlates and outcomes (Cillessen \& Rose, 2005; Mayeux, Houser, \& Dyches, 2011; Rodkin, Ryan, Jamison, \& Wilson, 2012). It should be noted, however, that the younger the studied age group, the more the two forms of popularity overlap (Cillessen \& Mayeux, 2004; Rodkin et al., 2012). Whereas ten- and thirteen-year-old children's descriptions of "popular children" (perceived popularity) included mentions of physical appearance, self-presentation, studentship, and peer affiliations, seven-year-old children described popular children as those who (a) are liked by others, (b) behave pro-socially, (c) are less overtly aggressive, and (d) are preferred playmates (Xie, Li, Boucher, Hutchins, \& Cairns, 2006). The popularity measure that we derived from peer nominations by seven- to eight-year-olds, who were asked to report on whom they enjoyed spending time with, is thus likely to reflect both the extent to which the child is liked and preferred, and the extent to which the child is central and visible.

Seven- to eight-year-olds are entering middle childhood. At this age, in between weaning and sexual maturity, peer relations and peer respect are of paramount importance among social primates (Del Giudice, Angeleri, \& Manera, 2009). The evolutionary purpose of this period can be derived from differences in its relative length in various primates. In essence, across various species of primates, the length of this period is associated with the complexity of social networks and the size of the brain area essential for social problem solving (the longer the period of juvenility, the larger the social networks and the non-visual neocortex: Joffe, 1997). For highly 
social primates, such as humans, who have to learn language, communication skills, and social hierarchies, in order to be able to survive (and later reproduce) within a social context (Joffe, 1997; Locke \& Bogin, 2006), a long middle childhood is necessary.

Several developmental processes occurring in middle childhood support the idea that peer relations are of particular importance in this age period. Whereas friendships before the age of seven have focused on playmate activities and gaining pleasure from games, group acceptance has been argued to be the most important function of friendship in the following years (Parker \& Gottman, 1989). Indeed, as cognitive advances allow for the construction of more complex selfrepresentations (Harter, 1998), based, for instance, on newly acquired perspective taking skills and social comparison processes (e.g., Eccles, 1999; Ruble, Boggiano, Feldman, \& Loebl, 1980; Wigfield et al., 1997), peer relations become increasingly important determinants of self-worth (e.g., Cole, Jacquez, \& Maschman, 2001; Hart \& Damon, 1986). Also supporting the notion that one's relationships to others, particularly peers and friends, become more important at this age is that the trait labels applied to the self become increasingly interpersonal (Rosenberg, 1979). In sum, gaining the liking, preference and respect of one's peers is likely to constitute one of the primary developmental goals of middle childhood. Difficulties at this task could, as we will argue below, have enduring consequences throughout the life course.

\section{Personality and Popularity}

The present research was conducted within the framework provided by the Big Five model of personality structure. There is, to our knowledge, no research on the associations between popularity and Big Five personality traits in a sample as young as ours. However, among adolescents and young adults, the associations between personality traits and popularity (any of the forms of popularity presented above) have been studied to substantial extent. Of the Big Five trait dimensions, Extraversion is by far the trait most often associated with popularity among adolescents (Ciarrochi \& Heaven, 2009; Jensen-Campbell et al., 2002; Jensen-Campbell \& Malcolm, 2007; 
Lubbers, Van Der Werf, Kuyper, \& Offringa, 2006; Scholte, Van Aken, \& Van Lieshout, 1997; van der Linden, Scholte, Cillessen, Nijenhuis, \& Segers, 2010) and young adults (Anderson, John, Keltner, \& Kring, 2001; Asendorpf \& Wilpers, 1998; Stopfer, Egloff, Nestler, \& Back, 2013; Wortman \& Wood, 2011). In fact, there seems to be only one study in which a non-significant association between Extraversion and popularity has been reported (Selfhout et al., 2010). Agreeableness has also, although less frequently, been associated with popularity in adolescence (Jensen-Campbell et al., 2002; Scholte et al., 1997) and young adulthood (Selfhout et al., 2010). There are mixed results for Conscientiousness among adolescents; one study reports a positive (Jensen-Campbell \& Malcolm, 2007) and another study a negative association (van der Linden et al., 2010). Some negative associations between Openness to Experience and popularity in adolescence have been reported, but mostly for reciprocal friendship measures, not for unilateral popularity (Jensen-Campbell et al., 2002; Jensen-Campbell \& Malcolm, 2007; Scholte et al., 1997). In addition, one study has reported a negative association between Neuroticism and popularity in early adulthood (Anderson et al., 2001).

Popularity could also be reflected in the size of one's social networks. Extraversion is the only personality trait associated with number of friends in online social networks (e.g. Facebook; Lönnqvist \& Itkonen, 2014; Stopfer et al., 2014). Although online social network samples include the whole adult population, they tend to be skewed towards young adults. These results thus provide additional support for the Extraversion-popularity link among young adults. Also, studies on the size of offline peer networks have indicated that Extraversion is the most relevant trait in this domain (Kalish \& Robins, 2006; Pollet, Roberts, \& Dunbar, 2011; Roberts, Wilson, Fedurek, \& Dunbar, 2008; Russell, Booth, Reed, \& Laughlin, 1997). Regarding other traits, one study has reported a negative association between neuroticism and social network size (Kalish \& Robins, 2006). In sum, the literature on adults and adolescents suggest that Extraversion is by far the most relevant Big Five personality trait in determining popularity. The present study aims to 
extend this literature by studying these associations at an earlier stage of development; that is, middle childhood.

Although the social consequences of Extraversion per se have not been studied in a sample as young as ours, Extraversion, like the other Big Five factors, has enormous bandwidth, and there are several characteristics associated with Extraversion that have been studied in the developmental psychology literature. For instance, positive mood, positive anticipation, approach motivation, desire for sensation-seeking, unrestraint, impulsiveness, activity level, dominance, leadership, warmth, and assertiveness, all of which have been argued to be constituents of Extraversion, have been investigated in children. Given our interest in social behavior, we focus our illustrative review of this literature on shyness. Shyness has been argued to be an important determinant of childhood peer relations (Rubin \& Mills, 1988), and is considered one of the most prototypical characteristics of extraverts - e.g., over $90 \%$ of expert judges suggested shyness captures the most central content of Extraversion (John, 1990), or to take another example, across 12 data sets comprising of both self- and peer-ratings, shyness, with a loading of -.79, was the item that most strongly defined the Extraversion factor (Saucier, 1994).

Although intuitively many attributes associated with popularity, such as assertiveness, sociability, and good communication skills, could seem incompatible with shyness, the empirical evidence on the associations between childhood shyness and popularity is at best mixed. Studies directly investigating the associations between shyness and popularity are very rare - only a handful of studies directly address this issue, and these studies have suffered from methodological limitations. For instance, Booth-LaForce and Oxford (2008), who documented a negative association between teacher ratings of shyness and teacher ratings of sociometric status, noted that although a measure of peer sociometric data would be ideal for research designs such as theirs, teacher ratings of children's social relationships were the current norm (e.g., Ladd, 2006; Ladd \& Burgess, 1999; Gazelle \& Ladd, 2003; Gazelle \& Rudolph, 2004). Very recently, Eggum-Wilkens, 
Valiente, Swanson, and Lemery-Chalfant (2014), who reported on a negative association between parent ratings of shyness and teacher ratings of popularity, noted that "a worthwhile next step to document this relation involves utilizing peer-reported (e.g., sociometric nominations) impressions of children's real-time social tendencies and popularity" (Eggum-Wilkens et al., 2014, p. 91). The literature on shyness and popularity thus suggests that they may be negatively associated in middle childhood, but empirical evidence employing peer-ratings of sociometric status is lacking. Furthermore, the one study that we could find that did utilize peer ratings of popularity found that shyness was unrelated to popularity (Bowen, Vitaro, Kerr, \& Pelletier, 1995). Despite this, based on the impressive amount of research conducted with older participants, in which an association between Extraversion and popularity has been documented, we expected Extraversion to be associated with popularity.

\section{Oral Fluency as a Mediator}

In his Annual Review of Psychology article published at the turn of the century, Funder (2001) called for more research connecting personality with actual real-life social behaviors. Five years later, Ozer and Benet-Martinez (2006), in the same journal, reviewed the evidence that had by then accumulated on the predictive power of personality on real-life outcomes, most of which were social by their nature. Most recently, Hampson (2012), in her Annual Review of Psychology article on the same topic, argued that the next goal of personality research should be to focus on the processes underlying the observed associations between personality traits and real-life outcomes (for a similar emphasis on the need to understand the processes through which personality is expressed, see, for instance, the PERSOC framework (Back et al., 2011) or the CAPS model (Mischel \& Shoda, 2008)). Hampson (2012) argued that the discovery of such processes should not only helps us improve our theoretical models of personality, but also help identify opportunities for intervention. The study of processes typically invokes mediation; a mediator is a trait-related action that is thought to bring about a change in an outcome (Rusting, 1998). In the present context, 
establishing a mechanism through which Extraversion influences popularity entails examining mediating behaviors that a) are manifestations of Extraversion b) influence peer regard and c) are observable or accessible to others. Below we argue that enhanced speech production, or oral fluency, could in middle childhood, be such a mediator variable.

One manifestation of Extraversion in social behavior is talkativeness (Mehl, Gosling, \& Pennebaker, 2006). But not only the quantity of speech that extraverts produce, but also its quality differentiates extraverts from introverts - research conducted within the zero-acquaintance personality perception framework shows that merely listening to a stranger allows for accurate judgments of his or her level of Extraversion (Borkenau \& Liebler, 1992; Hunt \& Lin, 1967; Scherer, 1978). More recently, the content of speech and strength of voice have, within the zeroacquaintance framework, been shown to differentiate extraverts from introverts - these features were associated with more positive ratings by strangers (Back et al., 2010). Corroborating these findings, further research has revealed that Extraversion and three of its facets (sociability, activity, and tendency to experience positive emotions) are associated with psychometrically assessed verbal fluency (Sutin et al., 2011). Extraverts have also been reported to have a more implicit speech style, a higher speech rate, and show less hesitation, especially under more stressful situations (Dewaele \& Furnham, 1999; 2000). Based on the above, we expected Extraversion to be associated with oral fluency.

For oral fluency to mediate the association between Extraversion and popularity, oral fluency needs to be associated with popularity. Although studies on adolescents have established that expressive language skills are associated with friendship quality (Botting \& Conti-Ramsden, 2008; Durkin \& Conti-Ramsden, 2007), there are rather few studies on individual differences in oral fluency and various social behaviors and outcomes in middle childhood. However, one study, conducted with a sample of five-year-old boys, suggested that verbal abilities predict peer popularity already in this age group (Braza et al., 2009). Further supporting the idea that verbal 
abilities matter already at this age, observation of preschool children has revealed that disliked children are less able to contribute to coherent conversation (Black \& Hazen, 1990). On a related note, disfluent children have been observed to be less able to communicate in social problem solving situations and are therefore less able to maintain or reconcile peer relations (Horowitz, Jansson, Ljungberg, \& Hedenbro, 2006). Experimental studies on children's perceptions of stuttering peers, adults and puppets have also supported the view that oral fluency is an important determinant of peer popularity. For instance, when rating videos of the same child either stuttering or not stuttering, the same child was rated as less likely to fit in and less likely to make friends when raters based their ratings on the video in which the child was stuttering (Evans, Healey, Kawai, \& Rowland, 2008). Similar results have been found among children who rated videos of an adult: the more the adult stuttered, the more negatively the children rated the adult (Franck, Jackson, Pimentel, \& Greenwood, 2003). Already preschool children rate disfluent puppets more negatively than they rate fluent puppets (Ezrati-Vinacour, Platzky, \& Yairi, 2001).

Oral fluency is likely to be a particularly strongly associated with popularity in middle childhood, an age period in which both peer relations (Del Giudice et al., 2009) and spoken language develop rapidly (e.g., Hoit, Hixon, Watson, \& Morgan, 1990), suggesting that there will be ample individual differences in these characteristics. Based on the above described findings, we expected oral fluency to be associated with popularity. More importantly, we expected oral fluency to mediate the association between Extraversion and popularity.

\section{The Role of Working Memory and Gender}

The fluent speech production of extraverts may, at least partially, be a product of better working memory functionality (Lieberman, 2000; Pearman, 2009). This line of thought builds on the idea that under more formal interpersonal conditions, introverts become over-aroused (Eysenck, 1974; Gray \& Braver, 2002), and also on the notion that working memory is associated with verbal fluency (Rosen \& Engle, 1997). Matthews, Deary, and Whiteman (2003) have proposed 
that the better working memory of extraverts may lead to better conversational skills, and consequently to more successful behavior in social environments. By contrast, it could be that introverts are less able to maintain fluency of speech in formal or stressful situations that require parallel processing of multiple stimuli (Dewaele \& Furnham, 2000). In more informal and less complex conditions the association between Extraversion and fluency is not as frequently reported, perhaps because there are less processes dividing attention and causing arousal (Dewaele \& Furnham, 2000). In short, extraverts may have an advantage in speech production because of better working memory (Matthews et al., 2003).

Based on the above, the association between Extraversion and oral fluency could, to some degree, be caused by individual differences in working memory capacity. The association between Extraversion and oral fluency would, if this were the case, be expected to be rendered insignificant when the influence of working memory is controlled for. An alternative possibility is that the enhanced oral fluency of extraverts is not only based on working memory processes, but also on their approach-oriented and attention attracting behavioral tendencies (Ashton, Lee, \& Paunonen, 2002; Gomez, Holmberg, Bounds, Fullarton, \& Gomez, 1999) that direct them towards more experiences in interpersonal communication. That is, because interpersonal engagement and social relations are more important for extraverts than for introverts, extraverts are likely to spend more time communicating with other people (see also Wilson, Harris, \& Vazire, 2015 in this volume for association between extraversion and interaction quantity among college students), thereby becoming more orally fluent. This would give them advantages in forming relations with peers and gaining popularity. Working memory was included in the present analyses in order to investigate whether the expected association between Extraversion and oral fluency is independent of working memory.

Research focusing on the peer processes of children has revealed the existence of gender differences in several domains (for a review, see: Rose \& Rudolph, 2006). More 
specifically, there are several studies suggesting that the associations between constructs associated with Extraversion (e.g., shyness) and popularity are stronger for boys (e.g., Coplan, Prakash, O’Neil, \& Armer, 2004). Also the link between verbal abilities and popularity may be stronger among boys (Braza et al., 2009). We therefore examined the possible moderating role of gender.

\section{Purpose of the present research}

The present research aimed to contribute to the growing literature on personality and social relations in several ways. We first investigated whether already seven- to eight-year-olds showed an association between Extraversion and popularity (we also investigated associations between other Big Five personality traits and popularity). Several of the currently most important frameworks within personality research; for instance, the PERSOC framework presented by Back et al., (2011), and the neosocioanalytic model presented by B. Roberts and Wood (2006), suggest that social interaction processes are not only influenced by personality dispositions, but that these processes also influence the development of dispositions. This is particularly likely to be true in childhood (there is general agreement that the stability of personality more or less linearly increases from childhood to adulthood; e.g., a meta-analysis by B. Roberts and DelVecchio (2001) suggested that the rank-order stability of personality traits in middle childhood was .43 , whereas it in older age groups was as high as .74). Prior research on how Extraversion is behaviorally manifested and the social consequences it may have has been conducted with adult and adolescent samples. Extending this research into middle childhood - an age period in which the acquisition of social skills and social competence is of paramount importance - could shed light on the life course development of Extraversion. For more exploratory purposes, relations between other personality traits and popularity were also investigated.

Knowledge about mediating mechanisms, such as social behaviors, is essential if we are to understand the associations between personality and social outcomes (Back et al., 2011). Moreover, such knowledge will identify opportunities for intervention (Hampson, 2012). Such 
interventions may be directed at changing the level or rate of growth of traits, or they may be directed at the processes through which traits are manifested in behavior. In the present research, we expected oral fluency to mediate the associations between Extraversion and popularity. From an applied perspective, focusing on oral fluency from the age at which children enter the school system may be particularly important as oral fluency may be a cumulative advantage that produces inequality throughout the school years (Baumert, Nagy, \& Lehmann, 2012; DiPrete \& Eirich, 2006). Cumulative advantages are various phenomena wherein initial levels of an attribute influence change rates of that same attribute subsequently (DiPrete \& Eirich, 2006). In the context of the current study, higher initial oral fluency could lead to faster gains in social skills later on orally fluent children will engage in social conversations more often, which will contribute to their popularity, possibly even their levels of Extraversion (Back et al., 2011; Hampson, 2012; B. Roberts \& Wood, 2006), which in turn will open up more opportunities for improving oral fluency as well as learning other social skills (Baumert et al., 2012). In fact, Black and Hazen (1990, p. 386) have proposed a similar pattern of reciprocated causality between communication and social status: “...it seems very likely that although only certain types of communication patterns may contribute to the original establishment of social status, once a particular social reputation is established, the relation of communication skills and social status becomes cyclic (i.e., low peer status leads to inadequate peer communication, which leads to low peer status, and so on)". Thus, the gap in social skills between orally fluent and less fluent children may widen throughout middle childhood. A similar phenomenon, known as the Matthew Effect, has previously been proposed for early reading abilities (Stanovich, 1986), which have been suggested to bring a cumulative advantage in learning throughout the school years.

As argued above, Working Memory could be involved in the association between Extraversion and oral fluency. We will investigate this possibility, as well as possible gender differences. As a final note, the ratings of oral fluency were obtained from the participants' teachers. In order to rule out alternative interpretations of the links between Extraversion, oral 
fluency, and popularity, we also investigated teachers' ratings of proficiency in other academic domains (skills in writing, reading, and mathematics). This enabled us to control for potential general desirability effects in teacher ratings, thereby allowing us concentrate on the unique effects of oral fluency.

\section{Methods}

\section{Participants and Procedure}

Our sample included 760 children from 38 school classes selected to be representative of the Helsinki (Finland) area (see Lönnqvist, Verkasalo, \& Vainikainen, 2011). These 760 children all took part in the sociometer procedure. Parent ratings of personality were available for 595 children, teacher ratings of academic skills were available for 550 children, and a working memory score was available for 699 children. The personality of the children was assessed at age seven, around half a year after school had started. More or less simultaneously, teacher assessments of oral fluency and academic skills were collected. One year later, when the children were eight, they completed a sociometer during class.

\section{Measures}

Personality. For the assessment of personality, parents rated the children on 27 personality descriptive items (see Table 1 in Lönnqvist et al., 2011) on a scale from 1 to $7 .{ }^{1}$ These items were used to assess Extraversion, Openness to Experience, Conscientiousness, Emotional Stability, Pro-sociality and Antagonism (Big Five Agreeableness split into two separate factors). In order to utilize as much of the variance as possible, we used factor scores rather than mean or sum scores. The two highest loading items on Extraversion - the factor that we focus most on - were 'She is good at asserting herself' and 'She states her opinions even when others disagree'. Descriptive statistics and inter-correlations for all our measures are presented in Table 1. 
Oral Fluency, Writing, Reading, and Mathematical Skills. Teachers assessed the children's Oral Fluency, as well as their Writing, Reading, and Mathematical Skills. Teachers were instructed to: 'assess the pupil's current skill levels in the following domains', which were then listed as 'oral fluency', 'writing', 'reading', and 'mathematical skill'. Each domain was assessed on a scale from 1 (the pupil has obvious difficulties) to 7 (the pupil is clearly above the developmental norm). Writing, Reading, and Mathematical Skills defined the Academic Skills variable that we employed (see below). ${ }^{2}$

Popularity. Popularity was assessed using a sociometer - in each class, children indicated who they preferred to work and play with. The nomination sheet was administered during class. Children provided nominations by answering three questions: 'With whom of your classmates do you prefer to... 1. Work in class? 2. Spend time with between classes? 3. Spend time with after school / spend leisure time with?' Nominations were limited to five per question, and popularity was computed as the sum of the received nominations. Children were allowed to nominate the same peer across different questions. ${ }^{3}$

Working Memory. Working memory was assessed using a count task that focused on short-term auditory memory. ${ }^{4}$ In this task (referred to as the Count Task by Lönnqvist et al., 2012) the teacher tapped his or her desk with a pencil, knuckle or palm, and the subjects had to write down how many knocks they heard. Counting and retrieving running totals involves working memory in the continuous registering of knocks and the retrieving of totals from the phonological store (Logie \& Baddelely, 1987). Participants were presented with 30 series of 1-5 taps in total. Each series was coded on a pass-fail basis ( 0 or 1$)$, so the scores ranged from zero to 30 . The distribution was strongly skewed to the left, so a rescaled version, with scores ranging from 0 to 6 , was used (similar to Lönnqvist et al., 2012).

\section{Statistical analyses}


Associations between variables were investigated with path analyses in structural equation modeling. To deal with missing values on some of the measures, full information maximum likelihood (FIML) estimation was used. This method, as compared to other methods, such as listwise deletion, pairwise deletion or imputation, has less restrictive assumptions regarding the pattern of missing values, and provides more efficient and unbiased parameter estimates (Enders \& Bandalos, 2001). All analyses were run in R v. 3.0.2 (The R Foundation for Statistical Computing, Vienna, Austria, http://www.r-project.org) using the R package Lavaan (Rosseel, 2012). Popularity was constructed as a latent variable on which the three nomination-variables loaded. Also Academic Skills, on which Writing, Reading and Mathematical Skills were set to load, was constructed as latent variable. ${ }^{5}$ Personality traits, oral fluency, and working memory were observed variables. All but parent ratings of personality were standardized within class to control for teachers' rating bias and manner of test-administration.

\section{Results}

We investigated whether parent ratings of personality traits, especially Extraversion, were associated with a) Popularity and b) Oral Fluency. To do this, a model was constructed in which paths from all six traits (Extraversion, Antagonism, Openness to experience, Conscientiousness, Pro-sociality and Emotional stability) to Popularity and to Oral Fluency were simultaneously estimated (see Figure 1). In a similar fashion, paths from personality traits to Academic Skills were simultaneously estimated. In addition, to examine whether, as we expected, Oral Fluency would predict Popularity, this path was estimated in the same model, as well as a path from Academic Skills to Popularity (the latter path was estimated in order to ensure that it was not the general desirability of the teacher ratings - reflected by Academic Skills - that was doing the explanatory work). Finally, Working Memory was included in the model as a control variable. Paths from Working Memory were estimated for Oral Fluency, Popularity and Academic Skills. Associations between personality traits and Working Memory were left out of the model because of 
non-significant zero-order correlations (all zero-order correlations between variables are shown in Table 1). Also the path from Working Memory to Extraversion was non-significant, and as it also did not affect other paths, it was left out of the final model. The fit of the model was acceptable $\left(\chi^{2}\right.$ $=96.972, d f=40, p<.05 ; C F I=.977, T L I=.960, R M S E A=.043, S R M R=.026)$. All of the indicator variables of popularity loaded statistically significantly on the latent factor (standardized loadings: .788 - .872). In addition, the indicator variables of Academic Skills all had statistically significant loadings (.532 for mathematics, .941 for writing, and .952 for reading). Path coefficients for the model are presented in Table 2 and in Figure 2. The paths from Extraversion $(\beta=.141, z=$ 3.273, $p<.01)$ and Antagonism $(\beta=-.153, z=-3.436, p<.01)$ to Popularity were significant, as well as were the paths from Extraversion $(\beta=.125, z=3.125, p<.01)$, Pro-sociality $(\beta=-.085, z=$ 2.092, $p<.05)$ and Academic skills $(\beta=.436, z=10.566, p<.001)$ to Oral Fluency. Working memory was significantly associated with all dependent variables in the model.

Extraversion was the only personality trait associated with both Popularity and Oral Fluency. Besides the personality traits mentioned above, also Oral Fluency explained unique variance in Popularity $(\beta=.158, z=3.106, p<.01)$. However, the path from Academic Skills to Popularity was non-significant. Of the personality traits, Conscientiousness was significantly associated with Academic Skill $(\beta=.120, z=2.532, p<.05)$. The above results show that Extraversion was associated with Popularity and with Oral Fluency. Furthermore, Extraversion was only associated with teacher ratings of Oral fluency, not with teacher ratings of more general Academic Skills, ruling out the possibility that the association between Extraversion and Oral Fluency would merely be an artifact of teachers evaluating extraverts more positively. Furthermore, the results show that the other teacher rated skills were not associated with popularity. Therefore, only Oral Fluency could serve as a mediator between personality and popularity. The results also show that the association between Extraversion and Oral Fluency was not affected by working memory. 
The above described results allowed us, in our examination of possible mediator variables, to focus exclusively on Oral Fluency as a potential mediator variable between Extraversion and Popularity. Using the same structural path model, the indirect effect combining the paths from (a) Extraversion to Oral Fluency, and from (b) Oral Fluency to Popularity was tested with a Sobel z-test. Sobel's test indicated that the indirect effect of Extraversion on Popularity through Oral Fluency was significant (standardized estimate: .020, $z=2.265, p<.05$ ). Furthermore, because the sampling distribution of Sobel's $\mathrm{z}$ is skewed, we further tested the mediation effect by constructing a population distribution for the indirect effect by drawing 5000 resamples from the original data (Preacher \& Hayes, 2008). This allowed us to calculate a bootstrapped confidence interval for the mediation estimate as well as for the other paths estimated above (MacKinnon \& Fairchild, 2009). The bootstrapped confidence intervals are presented in Table 2 . These generally supported the above analyses (for the Extraversion-Oral Fluency-Popularity mediation, the 95\% CI was .005-.040). The only path coefficient that was statistically significant in the above analyses, but which according to the bootstrapping method included zero in its CI, was the path from Prosociality to Oral Fluency $(95 \%$ CI: $-.171-.004)$. Based on these results, we conclude that the influence of Extraversion on Popularity is partially mediated through Oral Fluency. ${ }^{6}$

We finally conducted moderated mediation tests to examine if gender moderated the indirect effect of Extraversion on Popularity through Oral Fluency. The indirect effects were, in the same structural equation, estimated separately for girls $(\mathrm{N}=384)$ and boys $(\mathrm{N}=368)$, and the difference between these estimates was statistically tested in order to investigate whether it deviated from zero. Additionally, a sample distribution for gender difference was drawn by resampling the data 5000 times using the bootstrapping method, and, based on this distribution, a $95 \%$ confidence interval for the difference was calculated. Both the test for differences in the estimates (Difference $=$ $-.008, z=0.450, p=.653)$ and the confidence interval (95\% CI: $-0.045-0.029)$ indicated that gender did not moderate the indirect association between Extraversion and Popularity through Oral Fluency. 


\section{Discussion}

Based on previously reported links between (a) Extraversion and popularity, (b) Extraversion and verbal abilities, and (c) verbal abilities and popularity, we expected, in a sample of seven- to eight-year-olds, teacher rated oral fluency to mediate the association between parent rated Extraversion and sociometrically assessed popularity. The results conformed to our expectations. Furthermore, we concluded that the mediation was independent of working memory capacity, academic skills, and gender.

\section{Personality and Popularity}

Previous research on personality and popularity has established an association between Extraversion and popularity among adolescents (Ciarrochi \& Heaven, 2009; JensenCampbell et al., 2002; Lubbers et al., 2006; Scholte et al., 1997; van der Linden et al., 2010) and young adults (Anderson et al., 2001; Asendorpf \& Wilpers, 1998; Stopfer et al., 2013; Wortman \& Wood, 2011). However, the effects of Extraversion on popularity had not been investigated in an age group as young as ours. Furthermore, prior research conducted in this age group and employing concepts similar to Extraversion, such as shyness, has suffered from not employing actual peerratings, but has instead approximated sociometric popularity by means of adult ratings (see EggumWilkens et al., 2014). The current research thereby provides a novel contribution to the developmental psychology literature on individual differences associated with popularity in middle childhood. This is particularly important, because, as argued below, not only may individual differences in personality affect social interactions, but these interactions may, in the long run, also affect personality development, and this is especially likely to be true at a young age. Furthermore, what happens at this age may have consequences throughout the life course.

For more exploratory purposes, we also reported on associations between other personality traits and popularity. Parent ratings of Antagonism - the anti-social component of Big Five trait Agreeableness, as opposed to Pro-sociality, the pro social component - were negatively 
associated with popularity. Similar results connecting Agreeableness with popularity have previously been reported on in studies conducted with older participants - in fact, the associations between Agreeableness-related traits and popularity are the second most frequently reported associations in studies investigating associations between personality and popularity (JensenCampbell et al., 2002; Scholte et al., 1997; Selfhout et al., 2010).

\section{The Mediating Role of Oral Fluency}

The development of speech and the development of peer relations have been argued to be intrinsically associated, both in terms of phylogenetic and ontogenetic processes. The evolution of the human species into a social being for which belongingness is one of the most fundamental motivations (Baumeister \& Leary, 1995) is likely to have proceeded in tandem with the evolution of speech: among non-human primates, increases in vocal repertoire have co-evolved with increases in group size and social bonding (McComb \& Semple, 2005). Children entering middle childhood are likely to experience a dramatic increase in their social contacts. They are subject to a multitude of new situations in which fluent communication is likely to be rewarded, and that also provide them with opportunities to learn to communicate (Del Giudice et al., 2009; Joffe, 1997; Locke \& Bogin, 2006). In this age group, the development of spoken language is characterized by increased verbal fluency, gossip, argumentation and verbal duels (Del Giudice et al., 2009; Hoit et al., 1990). Our results are consistent with the idea of an intrinsic association between the development of speech production and the development of peer relations - at an age at which both speech and social networks are rapidly developing, those children whose acquisition of speech was more advanced also held an advantage in the social domain.

Our primary research question was whether the association between Extraversion and popularity was mediated through oral fluency. The results indicated that one reason that seven- to eight-year-old extraverts are more popular is, indeed, that they are more orally fluent. Importantly, the path between parent ratings of Extraversion and teacher ratings of oral fluency was not 
confounded by teacher ratings of other academic skills; that is, Extraversion explained unique variance in oral fluency. Our results therefore suggest that it was actually oral fluency that was relevant, not the general desirability of the teacher ratings. To our knowledge, no other variables have directly been proposed as mediators of the association between Extraversion and sociometric popularity.

Although our results provide an answer to the question of why extraverts are more popular, they can be accused of begging the question of why extraverts are more orally fluent. To investigate this, we considered the role of working memory. However, in contrast to previous research (Lieberman, 2000; Pearman, 2009), Extraversion was not associated with working memory, and controlling for working memory did not affect the associations between Extraversion, oral fluency, and popularity. That is, although working memory was independently associated with oral fluency, academic skills and popularity, the link between Extraversion and oral fluency was independent of working memory. The more fluent speech production of seven- to eight-year-old extraverts may thus primarily be a result of extraverts being more experienced in social interactions; i.e., extraverts may be more motivated to communicate with others and this may over the long run enhance their oral fluency.

Our results raise the possibility of a Matthew effect in the social domain. Extraverts are likely to show fast development in oral communication as they are likely to more eagerly seek opportunities for conversation - extraverts are by definition motivated to seek social attention (Ashton et al., 2002). The more socially active extraverts are, the more their oral fluency will develop, providing them with yet further opportunities to be socially active; for instance, both the general ability to contribute to conversations (Black \& Hazen, 1990), and more specific social skills, such as patching up peer relations (Horowitz et al., 2006), are facilitated by good verbal abilities. Furthermore, such social interaction processes may, especially at a young age, influence the development of Extraversion. In terms of the PERSOC framework (Back et al., 2011), those 
who are popular will have very different histories of social interaction processes than those who are less popular - children who are liked are likely to find social interactions more rewarding, and may therefore be more inclined to seek out and enter novel social situations. This may over time not only influence their levels of oral fluency (which will constantly be honed), but also their levels of Extraversion; i.e., as popular children's oral fluency improves, they will be more and more rewarded in social interactions, which could in turn lead them to enjoy social attention - arguably the core feature of Extraversion (Ashton et al., 2002) - even more. The interplay between Extraversion, oral fluency and popularity could thus be reciprocal, meaning that all three characteristics enhance each other (Black \& Hazen, 1990). Although the advantages of oral fluency may be more pronounced in the school years, early popularity, especially if it influences the development Extraversion, known to be associated with many positive life outcomes (Ozer \& Benet-Martinez, 2006), may continue to be a cumulative advantage throughout the life course (Nelson \& Dishion, 2004). Moreover, as the sources of self-worth shift in middle childhood (Harter, 1998) to become increasingly dependent on the appraisals derived from peers (Cole et al., 2001), the cumulative processes described above are also likely to have consequences for self-esteem, which in turn has been argued to play an important role in determining general quality of life (Swann, Chang-Schneider, \& McClarty, 2007).

It is important to note that full mediation did not occur. That is, the ability to produce fluent speech is not the only mechanism through which Extraversion affects popularity. Additional mediators should be sought to fully account for the association between Extraversion and popularity. For instance, behaviors that are automatically expressed across interpersonal situations by extraverts - such as expressions of positive mood and affect -could also be expected to mediate this association (Leikas, Lönnqvist, \& Verkasalo, 2012). It would also be highly interesting to investigate whether any of the extraverted behaviors associated with interpersonal attraction at zero acquaintance, such as active and assured movement, affects long-term popularity (Back et al., 2010). More generally, future research should include more potential mediator variables between 
traits and popularity - in order to disentangle the shared and unique effects of various processes through which traits influence social outcomes, and vice versa, several possible mediator variables need to be investigated simultaneously.

But not only additional mediators of the association between Extraversion and popularity should be sought - also the potential mechanisms that could link low Agreeableness with low popularity should be investigated. The literature on narcissism could provide some clues on where to look when investigating pathways from Extraversion and Agreeableness to social popularity. These two Big Five traits uniquely correspond to the two processes involved in grandiose narcissism - admiration and rivalry, respectively (Back et al., 2013). Admiration, characterized by striving for uniqueness, grandiose fantasies and charmingness, increases social potency through dominant and expressive behaviors, whereas rivalry, characterized by devaluation of others, aggressiveness and striving for supremacy, increases social conflict though aggressive and combative behaviors (Back et al., 2013; Back et al., 2010; Küfner, Nestler, \& Back, 2013). Although we do not wish to draw too strong parallels between the Big Five personality traits of seven-year-old children and narcissistic tendencies in adults, it is striking how it is particularly the low end of Agreeableness (i.e., Antagonism) that we found to be associated with (low) popularity. This implies that the mechanisms through which Agreeableness affects popularity are, also among children, likely to involve antagonistic and aggressive behaviors that increase social conflict, and not pro-social and cooperative behaviors that could be expected to facilitate more positive social outcomes (see also Ackerman \& Corretti (2015) in this volume for a presented mediator-lower valuing of interpersonal warmth-for negative association between Antagonism and interpersonal disclosure among college roommates).

\section{Limitations and Conclusions}

The design of the study does not allow for strong claims regarding causality. We acknowledge that more definite conclusions regarding causal processes will have to wait until the 
participants of the present research are followed up over time and we gain access to repeated measurements. Establishing whether a Matthew effect in the social domain actually exists and operates as a source of growing inequality throughout the school years is one of the main tasks of future research employing data collected on this sample of children.

Another methodological limitation was that oral fluency was measured with only one item. However, this item was positively associated with both working memory and with popularity. These associations, which replicate those previously reported on (e.g., Braza et al., 2009; Lieberman, 2000; Pearman, 2009), bolster our confidence in our measure of oral fluency. Nevertheless, more psychometrically sound measures of speech production should be utilized in future studies (e.g., Speeded Naming and Word Generation subtests of NEPSY II; Brooks, Sherman, \& Strauss, 2010).

The non-significant association between Extraversion and working memory differed from previous results (Lieberman, 2000; Pearman, 2009). The count test used for assessing working memory may not have been stressful and complex enough to induce arousal-differences between extroverts and introverts. Future research should address this issue more in detail; for instance by including various attention dividing social stimuli that would be expected to have stronger influence on working memory processes.

Despite several limitations, we do believe that the current result warrants the conclusion that in middle childhood - an age period in which peer relationships become of increasing importance- extraverted children are more popular in part because they are more orally fluent. Amplifying the importance of this finding, several of the currently most important frameworks within personality research (e.g., the PERSOC framework presented by Back et al., (2011); the neosocioanalytic model presented by B. Roberts and Wood (2006)) suggest that social interaction processes are not only influenced by personality dispositions, but that these processes also influence the development of dispositions (for the specific role that peers might play, see Reitz, 
Why are Extraverts more Popular? 25

Zimmerman, Hutteman, Specht, \& Neyer, 2014). Early discovery of those processes by which traits have their effects should help identify the best possible opportunities for intervention. Such discoveries could be used not only to bring about specific outcomes, but to bring about generally beneficial personality change. 


\section{Footnotes}

1. We also had access to teacher ratings of personality, but present the results only for parent ratings. The teacher ratings of personality were excluded because of shared method variance with teacher ratings of oral fluency, the proposed mediator variable. However, supporting the validity of the parent ratings, at least with regards to the two most important personality traits in the current research design (Extraversion and Antagonism), the parent-teacher correlations were: .41 for Extraversion, .41 for Antagonism, .40 for Conscientiousness, .22 for Openness to Experience, .18 for Pro-sociality and .10 for Emotional Stability (all significant, $p<.05$ ).

2. The validity of our one-item ratings of various skills could be questioned. However, a recent study conducted with some 2000 children showed that one-item teacher ratings of mathematical and language skills, very similarly phrased as the ratings that were employed in the present research, strongly predicted several tasks measuring mathematical thinking and reading comprehension, respectively (the amount of explained variance varied between twenty and thirty percent; see Krkovic, Greiff, Kupiainen, Vainikainen, \& Hautamäki, 2014). Moreover, even after controlling for cognitive ability, the same Reading Skills item that we employed predicted performance on the very comprehensive Learning to Learn test battery (Hautamäki et al., 2002), administered three (Vainikainen, 2014) and five years after the teacher ratings (Vainikainen, Wüstenberg, Kupiainen, Hotulainen, \& Hautamäki, 2014). Initial analyses of the Writing and Mathematical skills variables suggest that they show similar predictive power on future academic assessments (as would be expected based on the high inter-item correlations; see Table 1).

3. In the current literature, several different terms are used for sociometric peer nominations. Deriving the popularity measure from three different peer nominations may, therefore, give rise to some conceptual confusion. Positive nominations, such as those used in the present study, are often conceptualized as peer acceptance. By contrast, negative nominations are typically conceptualized as peer rejection (Gifford-Smith \& Brownell, 2003). Peer preference, or sociometric 
status/popularity can be computed as the difference between these two. However, drawing on evidence showing that the difference between sociometric popularity and perceived popularity is not clear at this age (Cillessen \& Mayeux, 2004; Xie et al., 2006), one could argue that negative nominations, such as "With whom of your classmates do you not prefer to spend time with after school?" could have the potential to confuse the children. Rather than employ this approach, we, in order to focus on popularity across contexts, as well to enhance reliability, employed three positive nominations referring to three different peer contexts. The specific nature of our sociometer measure should be kept in mind when interpreting the results and comparing them to those of other researchers.

4. Another Working Memory task (referred to as Memory Task by Lönnqvist, Vainikainen, and Verkasalo (2012)), designed to measure the capacity of the visuospatial sketchpad, was also entered, both separately and in combination with the Count Task, into the analyses that controlled for Working Memory. In addition, the Cognitive Ability summary index, formed from scores on six different cognitive tasks (see Lönnqvist et al. 2012), was also used as a control variable in all models. However, as the results for these models were virtually identical to the ones we present, only the results for the model including the Count task are presented here. This task was the only auditory working memory measure included in our battery of cognitive measures.

5. Academic Skills could quite plausibly be argued not to be a latent construct. Our purpose is not to imply that all academic skills reflect a general factor; rather, we constructed this variable only to control for the general positivity of the teacher ratings. We also ran analyses with alternative models that controlled only for one skill at a time (reading, writing and mathematics). These models produced results virtually identical to the ones that we present.

6. We estimated the same model using teacher ratings of personality instead of parent ratings. This model was highly similar to the model reported on in text. More specifically, the model fitted the data well $\left(\chi^{2}=141.884, d f=40, p<.05 ; C F I=.961, T L I=.932, R M S E A=.058\right.$, SRMR $\left.=.038\right)$. 
The pattern of significant paths also resembled to high degree the pattern that we present for parent ratings. Regarding the most important paths, Extraversion was associated with Oral Fluency ( $\beta=$ $.259, p<.001)$, and with Popularity $(\beta=.112, p<.05)$. Furthermore, the path from Oral Fluency to Popularity was statistically significant $(\beta=.118, p<.05)$. Sobel's test for an indirect effect from Extraversion to Popularity through Oral Fluency was also significant (standardized estimate: .031, $p$ $=.034$; bootstrapped 95\% CI: .004-.061). In sum, the same mediation effect that was obtained when employing parent ratings of personality was also obtained when employing teacher ratings of personality. However, there were also some differences in the path estimates. Most importantly, the path from teacher rating of Antagonism to Popularity was not significant $(\beta=-.093, p=.093$; bootstrapped 95\% CI: -.202-.020). In addition, teacher ratings of personality explained twice as much variance in teacher ratings of Academic Skills as did parent ratings $\left(R^{2}=.169\right.$ and $R^{2}=.085$, for teacher and parent ratings respectively; explaining this difference, teacher ratings of academic skills were much more strongly predicted by teacher ratings of Extraversion, Conscientiousness, Openness and Emotional Stability than by parent ratings of these same traits). To further establish the equivalence of the models, we ran an invariance test between the models employing teacher and parent ratings of personality. A model in which all path parameters, except those from personality to Academic Skills, were constrained to be identical across teacher and parent ratings showed no worse fit than a model in which these paths were allowed to vary $\left(\Delta \chi^{2}=19.880, d f=12, p=.07\right)$. These results indicate that the paths from personality traits to a) popularity and b) oral fluency were invariant across parent and teacher ratings of personality. Thus, our main results were not dependent on whether we employed parent or teacher ratings of personality. 


\section{References}

Ackerman, R. A., \& Corretti, C. A., (2015). Pathological personality traits and roommate relationship development dynamics. European Journal of Personality, 'THIS ISSUE; INSERT CORRECT PAGE NUMBERS WHEN DETERMINED

Anderson, C., John, O. P., Keltner, D., \& Kring, A. M. (2001). Who attains social status? Effects of personality and physical attractiveness in social groups. Journal of Personality and Social Psychology, 81, 116-132.

Asendorpf, J. B., \& Wilpers, S. (1998). Personality effects on social relationships. Journal of Personality and Social Psychology, 74, 1531-1544.

Ashton, M. C., Lee, K., \& Paunonen, S. V. (2002). What is the central feature of extraversion? Social attention versus reward sensitivity. Journal of Personality and Social Psychology, 83, $245-252$.

Back, M. D., Baumert, A., Denissen, J. J., Hartung, F.-M., Penke, L., Schmukle, S. C., . . Wrzus, C. (2011). PERSOC: A unified framework for understanding the dynamic interplay of personality and social relationships. European Journal of Personality, 25, 90-107.

Back, M. D., Küfner, A. C. P., Dufner, M., Gerlach, T. M., Rauthmann, J. F., \& Denissen, J. A. A. (2013). Narcissistic admiration and rivalry: Disentangling the bright and dark sides of narcissism. Journal of Personality and Social Psychology, 105, 1013-1037.

Back, M. D., Schmukle, S. C., \& Egloff, B. (2010). Why are narcissists so charming at first sight? Decoding the narcissism-popularity link at zero acquaintance. Journal of Personality and Social Psychology, 98, 132-145. 
Back, M. D., Schmukle, S. C., \& Egloff, B. (2011). A closer look at first sight: Social relations lens model analysis of personality and interpersonal attraction at zero acquaintance. European Journal of Personality, 25, 225-238.

Baumeister, R. F., \& Leary, M. R. (1995). The need to belong: Desire for interpersonal attachments as a fundamental human motivation. Psychological Bulletin, 117, 497-529.

Baumert, J., Nagy, G., \& Lehmann, R. (2012). Cumulative advantages and the emergence of social and ethnic inequality: Matthew effects in reading and mathematics development within elementary schools? Child Development, 83), 1347-1367.

Black, B., \& Hazen, N. L. (1990). Social status and patterns of communication in acquainted and unacquainted preschool children. Developmental Psychology, 26, 379-387.

Booth-LaForce, C., \& Oxford, M. L. (2008). Trajectories of social withdrawal from grades 1 to 6: Prediction from early parenting, attachment, and temperament. Developmental Psychology, 44, 1298-1313.

Borkenau, P., \& Liebler, A. (1992). Trait inferences: Sources of validity at zero acquaintance. Journal of Personality and Social Psychology, 62, 645-657.

Botting, N., \& Conti-Ramsden, G. (2008). The role of language, social cognition, and social skill in the functional social outcomes of young adolescents with and without a history of SLI. British Journal of Developmental Psychology, 26, 281-300.

Bowen, F., Vitaro, F., Kerr, M., \& Pelletier, D. (1995). Childhood internalizing problems: Prediction from kindergarten, effect of maternal overprotectiveness, and sex differences. Development and Psychopathology, 7, 481-498. 
Braza, F., Azurmendi, A., Muñoz, J. M., Carreras, M. R., Braza, P., García, A., . . Sánchez-Martín, J. R. (2009). Social cognitive predictors of peer acceptance at age 5 and the moderating effects of gender. British Journal of Developmental Psychology, 27, 703-716.

Brooks, B. L., Sherman, E. M. S., \& Strauss, E. (2010). NEPSY-II: A Developmental neuropsychological assessment, second edition. Child Neuropsychology, 16, 80-101.

Bukowski, W. M., Pizzamiglio, M. T., Newcomb, A. F., \& Hoza, B. (1996). Popularity as an affordance for friendship: The link between group and dyadic experience. Social Development, 5, 189-202.

Ciarrochi, J., \& Heaven, P. C. L. (2009). A longitudinal study into the link between adolescent personality and peer-rated likeability and adjustment: Evidence of gender differences. Journal of Research in Personality, 43, 978-986.

Cillessen, A. H., \& Mayeux, L. (2004). From censure to reinforcement: Developmental changes in the association between aggression and social status. Child Development, 75, 147-163.

Cillessen, A. H., \& Rose, A. J. (2005). Understanding popularity in the peer system. Current Directions in Psychological Science, 14, 102-105.

Cole, D. A., Jacquez, F. M., \& Maschman, T. L. (2001). Social origins of depressive cognitions: A longitudinal study of self-perceived competence in children. Cognitive Therapy and Research, $25,377-395$.

Coplan, R. J., Prakash, K., O'Neil, K., \& Armer, M. (2004). Do you "want" to play? Distinguishing between conflicted shyness and social disinterest in early childhood. Developmental Psychology, 40, 244-258.

Del Giudice, M., Angeleri, R., \& Manera, V. (2009). The juvenile transition: A developmental switch point in human life history. Developmental Review, 29, 1-31. 
Dewaele, J. -M., \& Furnham, A. (1999). Extraversion: The unloved variable in applied linguistic research. Language Learning, 49, 509-544.

Dewaele, J. -M., \& Furnham, A. (2000). Personality and speech production: A pilot study of second language learners. Personality and Individual Differences, 28, 355-365.

Diprete, T. A., \& Eirich, G. M. (2006). Cumulative advantage as a mechanism for inequality: A review of theoretical and empirical developments. Annual Review of Sociology, 32, 271-297.

Durkin, K., \& Conti-Ramsden, G. (2007). Language, social behavior, and the quality of friendships in adolescents with and without a history of specific language impairment. Child Development, $78,1441-1457$.

Eccles, J. S. (1999). The development of children ages 6 to 14. The future of children, 9, 30-44.

Eggum-Wilkens, N. D., Valiente, C., Swanson, J., \& Lemery-Chalfant, K. (2014). Children's shyness, popularity, school liking, cooperative participation, and internalizing problems in the early school years. Early Childhood Research Quarterly, 29, 85-94.

Enders, C. K., \& Bandalos, D. L. (2001). The relative performance of full information maximum likelihood estimation for missing data in structural equation models. Structural Equation Modeling, 8, 430-457.

Evans, D., Healey, E. C., Kawai, N., \& Rowland, S. (2008). Middle school students' perceptions of a peer who stutters. Journal of Fluency Disorders, 33, 203-219.

Eysenck, M. W. (1974). Extraversion, arousal, and retrieval from semantic memory. Journal of Personality, 42, 319-331.

Ezrati-Vinacour, R., Platzky, R., \& Yairi, E. (2001). The young child's awareness of stuttering-like disfluency. Journal of Speech, Language, and Hearing Research, 44, 368-380. 
Franck, A. L., Jackson, R. A., Pimentel, J. T., \& Greenwood, G. S. (2003). School-age children's perceptions of a person who stutters. Journal of Fluency Disorders, 28, 1-15. Funder, D. C. (2001). Personality. Annual Review in Psychology, 52, 197-221.

Gazelle, H., \& Ladd, G. W. (2003). Anxious solitude and peer exclusion: A diathesis-stress model of internalizing trajectories in childhood. Child Development, 74, 257-278.

Gazelle, H., \& Rudolph, K. D. (2004). Moving toward and away from the world: Social approach and avoidance trajectories in anxious solitary youth. Child Development, 75, 829-849.

Gifford-Smith, M. E., \& Brownell, C. A. (2003). Childhood peer relationships: Social acceptance, friendships, and peer networks. Journal of School Psychology, 41, 235-284.

Gomez, R., Holmberg, K., Bounds, J., Fullarton, C., \& Gomez, A. (1999). Neuroticism and extraversion as predictors of coping styles during early adolescence. Personality and Individual Differences, 27, 3-17.

Gray, J. R., \& Braver, T. S. (2002). Personality predicts working-memory-related activation in the caudal anterior cingulate cortex. Cognitive, Affective and Behavioral Neuroscience, 2, 64-75.

Hart, D., \& Damon, W. (1986). Developmental trends in self-understanding. Social Cognition, 4, $388-407$.

Harter, S. (1998). The development of self-representations. In N. Eisenberg (Ed.), Handbook of child psychology (Vol. 3, pp. 553-617). New York: John Wiley.

Hautamäki, J., Arinen, P., Eronen, S., Hautamäki, A., Kupiainen, S., Lindblom, B., Niemivirta, M., Pakaslahti, L., Rantanen, P., Scheinin, P. (2002). Assessing Learning-to-learn: A Framework. Helsinki: National Board of Education, Evaluation 4/2002. 
Hampson, S. E. (2012). Personality processes: Mechanisms by which personality traits "get outside the skin". Annual Review of Psychology, 63, 315-339.

Hoit, J. D., Hixon, T. J., Watson, P. J., \& Morgan, W. J. (1990). Speech breathing in children and adolescents. Journal of Speech and Hearing Research, 33, 51-69.

Horowitz, L., Jansson, L., Ljungberg, T., \& Hedenbro, M. (2006). Interaction before conflict and conflict resolution in pre-school boys with language impairment. International Journal of Language and Communication Disorders, 41, 441-466.

Hunt, R. G., \& Lin, T. K. (1967). Accuracy of judgments of personal attributes from speech. Journal of Personality and Social Psychology, 6, 450-453.

Jensen-Campbell, L. A., \& Malcolm, K. T. (2007). The importance of conscientiousness in adolescent interpersonal relationships. Personality and Social Psychology Bulletin, 33, 368383.

Jensen-Campbell, L. A., Adams, R., Perry, D. G., Workman, K. A., Furdella, J. Q., \& Egan, S. K. (2002). Agreeableness, extraversion, and peer relations in early adolescence: Winning friends and deflecting aggression. Journal of Research in Personality, 36, 224-251.

Joffe, T. H. (1997). Social pressures have selected for an extended juvenile period in primates. Journal of Human Evolution, 32, 593-605.

John, O. P. (1990). The search for basic dimensions of personality. In P. McReynolds, J. C. Rosen, \& G. J. Chelune (Eds.), Advances in psychological assessment (pp. 1-37). Springer US.

Kalish, Y., \& Robins, G. (2006). Psychological predispositions and network structure: The relationship between individual predispositions, structural holes and network closure. Social Networks, 28, 56-84. 
Krkovic, K., Greiff, S., Kupiainen, S., Vainikainen, M. P., \& Hautamäki, J. (2014). Teacher evaluation of student ability: what roles do teacher gender, student gender, and their interaction play? Educational Research, 56, 244-257.

Küfner, A. C. P., Nestler, S., Back, M. D. (2013). The two pathways to being an (un-)popular narcissist. Journal of Personality, 81, 184-195.

Ladd, G. W., \& Burgess, K. B. (1999). Charting the relationship trajectories of aggressive, withdrawn, and aggressive/withdrawn children during early grade school. Child Development, 70, 910-929.

Ladd, G. W. (2006). Peer rejection, aggressive or withdrawn behavior, and psychological maladjustment from ages 5 to 12: An examination of four predictive models. Child Development, 77, 822-846.

Leikas, S., Lönnqvist, J.-E., Verkasalo, M. (2012). Persons, situations, and behaviors: Consistency and variability of different behaviors in four interpersonal situations. Journal of Personality and Social Psychology, 103, 1007-1022.

Lieberman, M. D. (2000). Introversion and working memory: Central executive differences. Personality and Individual Differences, 28, 479-486.

Locke, J. L., \& Bogin, B. (2006). Language and life history: A new perspective on the development and evolution of human language. Behavioral and Brain Sciences, 29, 259-280.

Logie, R. H., \& Baddeley, A. D. (1987). Cognitive Processes in Counting. Journal of Experimental Psychology: Learning, Memory, and Cognition, 13, 310-326.

Lubbers, M. J., Van Der Werf, M. P. C., Kuyper, H., \& Offringa, G. J. (2006). Predicting peer acceptance in Dutch youth: A multilevel analysis. Journal of Early Adolescence, 26, 4-35. 
Lönnqvist, J.-E., \& Itkonen, J. V. (in press). It's all about Extraversion: Why Facebook friend count doesn't count towards well-being. Journal of Research in Personality.

Lönnqvist, J.-E., Vainikainen, M.-P., \& Verkasalo, M. (2012). Teacher and parent ratings of sevenyear-old children's personality and psychometrically assessed cognitive ability. European Journal of Personality, 26, 504-514

Lönnqvist, J.-E., Verkasalo, M., \& Vainikainen, M.-P. (2011). Parent-teacher agreement on 7-yearold children's personality. European Journal of Personality, 25, 306-316.

MacKinnon, D. P., \& Fairchild, A. J. (2009). Current directions in mediation analysis. Current Directions in Psychological Science, 18, 16-20.

Matthews, G., Deary, I. J., \& Whiteman, M. C. (2003). Personality traits. Cambridge University Press.

Mayeux, L., Houser, J. J., \& Dyches, K. D. (2011). Social acceptance and popularity: Two distinct forms of peer status. In A. H. Cillessen, D. Schwartz \& L. Mayeux (Eds.), Popularity in the peer system (pp. 79-103). New York: Guilford Press.

McComb, K., \& Semple, S. (2005). Coevolution of vocal communication and sociality in primates. Biology Letters, 1, 381-385.

Mehl, M. R., Gosling, S. D., \& Pennebaker, J. W. (2006). Personality in its natural habitat: Manifestations and implicit folk theories of personality in daily life. Journal of Personality \& Social Psychology, 90, 862-877.

Mischel, W., \& Shoda, Y. (2008). Toward a unified theory of personality. In O. P. John, R. W. Robins, \& L. A. Pervin (Eds.), Handbook of personality: Theory and Research (pp. 208-241). New York: Guilford Press. 
Nelson, S. E., \& Dishion, T. J. (2004). From boys to men: Predicting adult adaptation from middle childhood sociometric status. Development and Psychopathology, 16, 441-459.

Ozer, D.J., \& Benet-Martínez, V. (2006). Personality and the prediction of consequential outcomes. Annual Review of Psychology, 57, 401-421.

Parkhurst, J. T., \& Hopmeyer, A. (1998). Sociometric popularity and peer-perceived popularity two distinct dimensions of peer status. The Journal of Early Adolescence, 18, 125-144.

Parker, J. G., and Gottman, J. M. (1989). Social and emotional development in a relational context: Friendship interaction from early childhood to adolescence. In Brendt, T., and Ladd, G. (eds.), Peer Relationships in Child Development, Wiley, New York, pp. 95-131.

Parsons, J. E., \& Ruble, D. N. (1977). The development of achievement-related expectancies. Child Development, 48, 1075-1079.

Pearman, A. (2009). Basic cognition in adulthood: Combined effects of sex and personality. Personality and Individual Differences, 47, 357-362.

Pollet, T. V., Roberts, S. G. B., \& Dunbar, R. I. M. (2011). Extraverts have larger social network layers: But do not feel emotionally closer to individuals at any layer. Journal of Individual Differences, 32, 161-169.

Preacher, K. J., \& Hayes, A. F. (2008). Asymptotic and resampling strategies for assessing and comparing indirect effects in multiple mediator models. Behavior Research Methods, 40, 879891.

Reitz, A. K., Zimmermann, J., Hutteman, R., Specht, J., \& Neyer, F. J. (2014). How Peers Make a Difference: The Role of Peer Groups and Peer Relationships in Personality Development. European Journal of Personality, 28, 279-288. 
Roberts, B. W., \& DelVecchio, W. F. (2000). The rank-order consistency of personality traits from childhood to old age: A quantitative review of longitudinal studies. Psychological Bulletin, $126,3-25$.

Roberts, B. W., \& Wood, D. (2006). Personality development in the context of the neosocioanalytic model of personality. In D. K. Mroczek \& T. D. Little (Eds.), Handbook of personality development (pp. 11-41). Mahwah, NJ: Erlbaum.

Roberts, S. G. B., Wilson, R., Fedurek, P., \& Dunbar, R. I. M. (2008). Individual differences and personal social network size and structure. Personality and Individual Differences, 44, 954964.

Rodkin, P. C., Ryan, A. M., Jamison, R., \& Wilson, T. (2012). Social goals, social behavior, and social status in middle childhood. Developmental Psychology, 49, 1139-1150.

Rose, A. J., \& Rudolph, K. D. (2006). A review of sex differences in peer relationship processes: Potential trade-offs for the emotional and behavioral development of girls and boys. Psychological Bulletin, 132, 98-131.

Rosen, V. M., \& Engle, R. W. (1997). The role of working memory capacity in retrieval. Journal of Experimental Psychology: General, 126, 211-227.

Rosenberg, M. (1979). Conceiving the self. New York: Basic Books.

Rosseel, Y. (2012). lavaan: An R package for structural equation modeling. Journal of Statistical Software, 48(2), 1-36. url: http://www.jstatsoft.org/v48/i02/

Rubin, K. H., \& Mills, R. S. L. (1988). The many faces of social isolation in childhood. Journal of Consulting and Clinical Psychology, 56, 916-924. 
Ruble, D. N., Boggiano, A. K., Feldman, N. S., \& Loebl, J. H. (1980). Developmental analysis of the role of social comparison in self-evaluation. Developmental Psychology, 16, 105-115.

Russell, D. W., Booth, B., Reed, D., \& Laughlin, P. R. (1997). Personality, social networks, and perceived social support among alcoholics: A structural equation analysis. Journal of Personality, 65, 649-692.

Rusting, C. L. (1998). Personality, mood, and cognitive processing of emotional information: Three conceptual frameworks. Psychological Bulletin, 124, 165-196.

Saucier, G. (1994). Mini-markers: a brief version of Goldberg's unipolar big-five markers. Journal of Personality Assessment, 63, 506-516.

Scherer, K. R. (1978). Personality inference from voice quality: The loud voice of extroversion. European Journal of Social Psychology, 8, 467-487.

Scholte, R. H. J., Van Aken, M. A. G., \& Van Lieshout, C. F. M. (1997). Adolescent personality factors in self-ratings and peer nominations and their prediction of peer acceptance and peer rejection. Journal of Personality Assessment, 69, 534-554.

Selfhout, M., Burk, W., Branje, S., Denissen, J., van Aken, M., \& Meeus, W. (2010). Emerging late adolescent friendship networks and big five personality traits: A social network approach. Journal of Personality, 78, 509-538.

Stanovich, K. E. (1986). Matthew effects in reading: Some consequences of individual differences in the acquisition of literacy. Reading Research Quarterly, 21, 360-407.

Stopfer, J. M., Egloff, B., Nestler, S., \& Back, M. D. (2013). Being popular in online social networks: How agentic, communal, and creativity traits relate to judgments of status and liking. Journal of Research in Personality, 47, 592-598. 
Stopfer, J. M., Egloff, B., Nestler, S., Back, M. D. (2014). Personality expression and impression formation in online social networks: An integrative approach to understanding the processes of accuracy, impression management and meta-accuracy. European Journal of Personality, 28, 73-94.

Sutin, A. R., Terracciano, A., Kitner-Triolo, M. H., Uda, M., Schlessinger, D., \& Zonderman, A. B. (2011). Personality traits prospectively predict verbal fluency in a lifespan sample. Psychology and Aging, 26, 994-999.

Swann, W. B., Jr., Chang-Schneider, C., \& McClarty, K. (2007). Do people's self-views matter? Self-concept and self-esteem in everyday life. American Psychologist, 62, 84-94.

Vainikainen, M.-P. (2014). Finnish primary school pupils' performance in learning to learn assessments: A longitudinal perspective on educational equity. Research Reports 360. University of Helsinki, Department of Teacher Education. Helsinki: Unigrafia

Vainikainen, M.-P., Wüstenberg, S., Kupiainen, S., Hotulainen, R., \& Hautamäki, J. (in press). Development of learning to learn skills in primary school. International Journal of Lifelong Education.

van der Linden, D., Scholte, R. H. J., Cillessen, A. H. N., Nijenhuis, J. T., \& Segers, E. (2010). Classroom ratings of likeability and popularity are related to the big five and the general factor of personality. Journal of Research in Personality, 44, 669-672.

Wigfield, A., Eccles, J. S., Yoon, K. S., Harold, R. D., Arbreton, A. J., Freedman-Doan, C., \& Blumenfeld, P. C. (1997). Change in children's competence beliefs and subjective task values across the elementary school years: A 3-year study. Journal of Educational Psychology, 89, 451-469. 
Wilson, R. E., Harris, K., \& Vazire, S. (2015). Personality and friendship satisfaction. European Journal of Personality, 'THIS ISSUE; INSERT CORRECT PAGE NUMBERS WHEN DETERMINED

Wortman, J., \& Wood, D. (2011). The personality traits of liked people. Journal of Research in Personality, 45, 519-528.

Xie, H., Li, Y., Boucher, S. M., Hutchins, B. C., \& Cairns, B. D. (2006). What makes a girl (or a boy) popular (or unpopular)? African American children's perceptions and developmental differences. Developmental Psychology, 42, 599-612. 
Table 1. Descriptive statistics and inter-correlations (pairwise) between variables

\begin{tabular}{|c|c|c|c|c|c|c|c|c|c|c|c|c|c|c|c|}
\hline Variables & 1 & 2 & 3 & 4 & 5 & 6 & 7 & 8 & 9 & 10 & 11 & 12 & 13 & 14 & 15 \\
\hline 1. Gender (1 girls, 2 boys) & - & & & & & & & & & & & & & & \\
\hline 2. Extraversion & -.016 & - & & & & & & & & & & & & & \\
\hline 3. Antagonism & $.190^{* *}$ & $.094 *$ & - & & & & & & & & & & & & \\
\hline 4. Conscientiousness & $-.140 * *$ & .028 & $-.111 * *$ & - & & & & & & & & & & & \\
\hline 5. Openness to Experience & $-.164 * *$ & .033 & -.039 & $-.108 * *$ & - & & & & & & & & & & \\
\hline 6. Pro-sociality & $-.116 * *$ & .002 & .019 & -.066 & .042 & - & & & & & & & & & \\
\hline 7. Emotional Stability & .028 & .030 & $-.259 * *$ & -.024 & -.038 & .010 & - & & & & & & & & \\
\hline 8. Oral Fluency & -.044 & $.123 * *$ & .035 & .043 & $.094 *$ & -.057 & .005 & - & & & & & & & \\
\hline 9. Writing skill & $-.119^{* *}$ & -.053 & -.060 & $.140 * *$ & $.102 *$ & .029 & -.068 & $.416^{* *}$ & 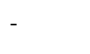 & & & & & & \\
\hline 10. Mathematical Skill & $.163^{* *}$ & -.023 & .008 & .060 & .085 & -.012 & .091 & $.413 * *$ & $.486 * *$ & - & & & & & \\
\hline 11. Reading Skill & -.049 & -.001 & -.034 & $.124 * *$ & $.095^{*}$ & .011 & -.035 & $.431^{* *}$ & $.896^{* *}$ & $.507^{* *}$ & - & & & & \\
\hline 12. Working Memory & -.068 & -.008 & -.053 & .067 & .023 & .070 & -.006 & $.220^{* *}$ & $.243 * *$ & $.247 * *$ & $.221 * *$ & - & & & \\
\hline 13. Nominations 1 & -.023 & $.097 *$ & $-.151 * *$ & $.099^{*}$ & .025 & .034 & $.085^{*}$ & $.243^{* *}$ & $.162^{* *}$ & $.138^{* *}$ & $.165^{* *}$ & $.169^{* *}$ & - & & \\
\hline 14. Nominations 2 & .009 & $.138^{* * *}$ & $-.130^{* *}$ & .073 & -.040 & .039 & $.106 * *$ & $.171 * *$ & $.090^{*}$ & $.091^{*}$ & $.119^{* *}$ & $.110 * *$ & $.740^{* *}$ & - & \\
\hline 15. Nominations 3 & .006 & $.123 * *$ & $-.113 * *$ & .060 & -.052 & -.010 & .042 & $.130^{* *}$ & $.086^{*}$ & .065 & $.108^{*}$ & $.155^{* *}$ & $.674 * *$ & $.664 * *$ & - \\
\hline Mean & 1.489 & 3.974 & 3.967 & 3.732 & 4.174 & 6.915 & 1.892 & 0.000 & 0.000 & 0.000 & 0.000 & 0.000 & 0.000 & 0.000 & 0.000 \\
\hline Std. Deviation & 0.500 & 1.242 & 1.329 & 1.240 & 0.928 & 0.943 & 1.195 & 0.973 & 0.973 & 0.973 & 0.973 & 0.973 & 0.975 & 0.975 & 0.975 \\
\hline
\end{tabular}

Note. ${ }^{*} p<.05 . * * p<.01$, Nominations 1 (in class sociometer), 2 (in between classes sociometer) and 3 (after school/leisure time sociomoter). 
Table 2. Standardized path coefficients and indirect effects from structural equation with parent ratings of personality

\begin{tabular}{|c|c|c|c|c|c|c|}
\hline \multirow[b]{3}{*}{ Independent variable } & \multicolumn{6}{|c|}{$\underline{\text { Dependent variable }}$} \\
\hline & \multicolumn{2}{|c|}{ Oral Fluency $\left(\mathrm{R}^{2}=24.7 \%\right)$} & \multicolumn{2}{|c|}{ Popularity $\left(\mathrm{R}^{2}=12.5 \%\right)$} & \multicolumn{2}{|c|}{ Academic Skills $\left(\mathrm{R}^{2}=8.5 \%\right)$} \\
\hline & Estimate & $(95 \% \mathrm{CI})$ & Estimate & $(95 \% \mathrm{CI})$ & Estimate & $(95 \% \mathrm{CI})$ \\
\hline Extraversion & $.125^{* * *}$ & $(.048-.204)$ & $.141^{* *}$ & $(.060-.220)$ & -.036 & $(-.121-.057)$ \\
\hline Antagonism & .053 & $(-.036-.136)$ & $-.153^{* *}$ & $(-.237--.068)$ & -.036 & $(-.129-.062)$ \\
\hline Conscientiousness & -.024 & $(-.110-.059)$ & .055 & $(-.035-.149)$ & $.120^{*}$ & $(.029-.216)$ \\
\hline Openness to Experience & .035 & $(-.054-.117)$ & -.042 & $(-.130-.040)$ & .086 & $(-.003-.183)$ \\
\hline Pro-sociality & $-.085^{*}$ & $(-.171-.004)$ & .039 & $(-.045-.123)$ & .009 & $(-.094-.105)$ \\
\hline Emotional stability & .032 & $(-.049-.112)$ & .060 & $(-.026-.145)$ & -.041 & $(-.136-.061)$ \\
\hline Working Memory & $.121^{* *}$ & $(.045-.201)$ & $.118^{* *}$ & $(.032-.194)$ & $.231^{* * *}$ & $(.141-.313)$ \\
\hline Academic Skills & $.436^{* * *}$ & $(.352-.519)$ & .059 & $(-.043-.164)$ & & \\
\hline Oral Fluency & & & $.158^{* *}$ & $(.062-.253)$ & & \\
\hline \multicolumn{7}{|c|}{ Indirect effect: Extraversion - Oral Fluency - Popularity } \\
\hline & $\begin{array}{l}\text { Estimate } \\
.020^{*}\end{array}$ & $\begin{array}{l}(95 \% \mathrm{CI}) \\
(.005-.040)\end{array}$ & & & & \\
\hline $\begin{array}{l}\text { Note. } * p<.05 . * * \\
95 \% \text { confidence in } \\
\text { bootstrapped resam } \\
\text { variable. }\end{array}$ & $\begin{array}{l}\text { vals for } \\
\text { es from }\end{array}$ & $\begin{array}{l}* *<<.001 . p \\
\text { the standardi } \\
\text { the original } d\end{array}$ & for & $\begin{array}{l}\text { irect effect } \\
\text { (in parenth } \\
\text { otal varianc }\end{array}$ & $\begin{array}{l}\text { lculated } \\
\text { vere esti } \\
\text { ained in }\end{array}$ & $\begin{array}{l}\text { with Sobel's t } \\
\text { mated using } 5( \\
\text { dependent }\end{array}$ \\
\hline
\end{tabular}




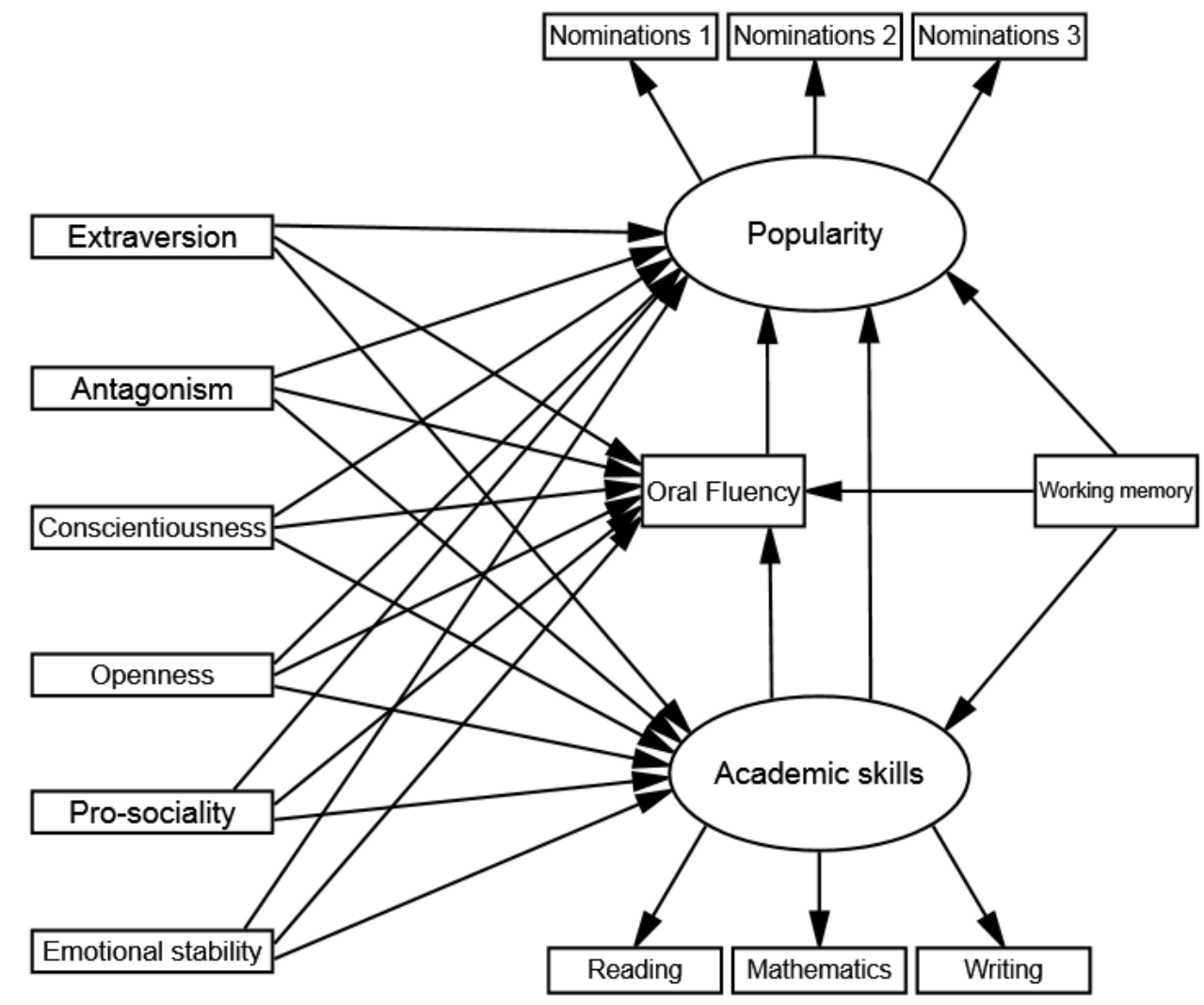

Figure 1. Structural path model used for examining the associations between parent ratings of personality traits, teacher ratings of oral fluency and popularity based on sociometric peer nominations. The model controls for general academic skills and working memory. 


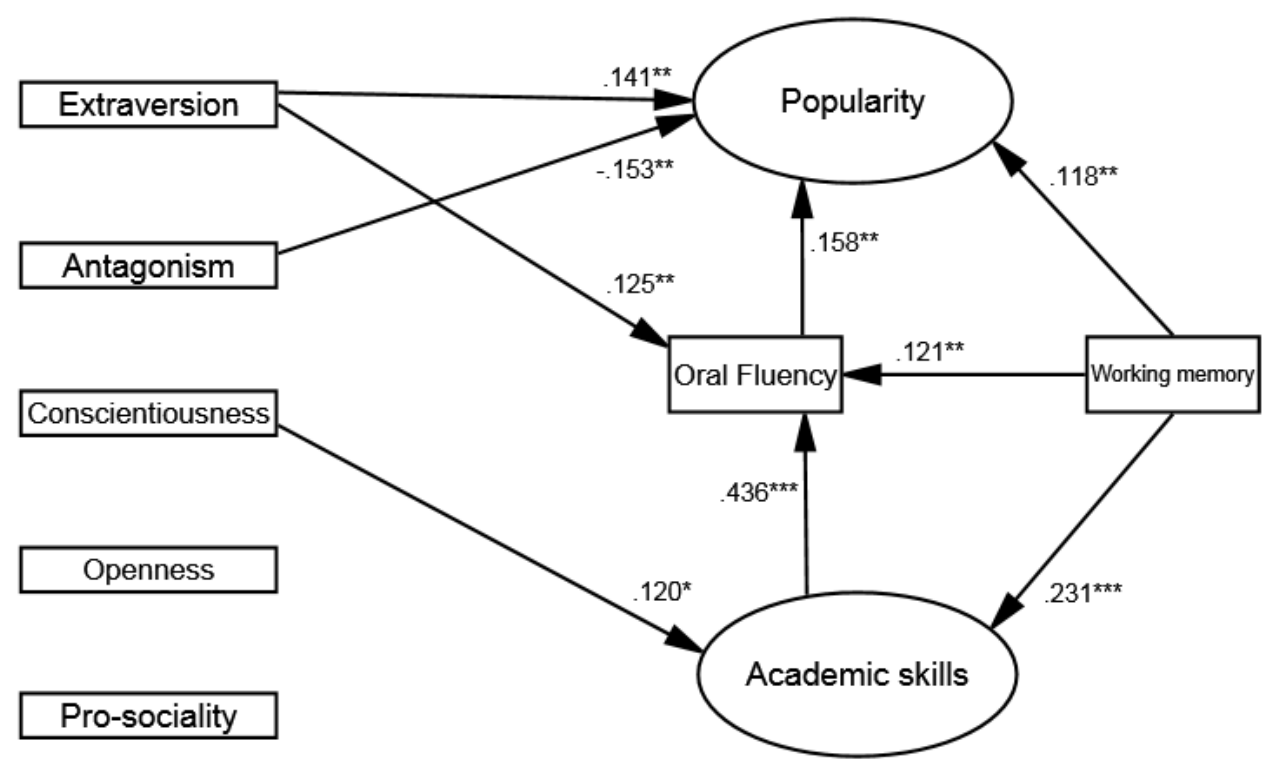

Emotional stability

Figure 2. Standardized estimates for structural path model. Only statistically significant (based on both z-test and bootstrapped 95\% confidence intervals) are depicted in the figure. 